\title{
HIV and HBsAg Seropositivity Amongst Patients Presenting for Ocular Surgery at a Tertiary Eye Care Hospital in Nigeria
}

\author{
M.B. Alhassan*, P. Unung and G.O. Adejor \\ National Eye Centre, PMB 2267, Western ByePass, Kaduna, Nigeria
}

\begin{abstract}
Background: The prevalence of HIV/AIDS and HBsAg sero-positivity is very high in sub-Saharan African. There is a risk of horizontal transmission of these diseases amongst ophthalmic patients.

Aim: To determine the proportion patients for eye surgery who are HIV/AIDS and HBsAg sero-positive at the National Eye Centre, Kaduna, Nigeria.

Methods: Patients selected for eye surgery during a surgical camp at the National Eye Centre, Kaduna were counseled for Voluntary Counseling and Testing (VCT) and HBsAg to determine their viral status.

Results: A total of 650 patients who were selected were screened. The distributions of the indications for selection were as follows: cataract 483 (74.3\%); glaucoma $44(6.8 \%)$ and pterygium $123(18.9 \%)$. Two patients $(0.2 \%)$ were found to be HIV seropositive while 11 (1.5\%) were HbsAg positive.

Conclusion: Pre-operative screening of all patients going for ophthalmic surgery for HIV and HbsAg may be desirable in our environment.
\end{abstract}

Keywords: HIV, HBsAg, ocular surgery, seroprevalence, Nigeria.

\section{BACKGROUND}

Ophthalmic surgeries are among the most performed surgeries worldwide. The indications for the surgery in ophthalmology include amongst other cataract (loss of clarity of the crystalline lens); glaucoma (characterized by progressive loss of optic nerve head tissue and constriction of the visual field); retinal detachment; squints and refractive errors, pterygium, globe lacerations from trauma, cornea foreign bodies and lid abnormalities like entropion.

The prevalence of HIV/AIDS and HBsAg sero-positivity is very high in sub-Saharan African [1-4]. Many patients undergoing eye surgery do not know their viral status. Thus there is a risk of horizontal transmission of these diseases amongst ophthalmic patients and eye care providers. We aimed to determine the proportion of patients for eye surgery who were HIV/AIDS and HBsAg sero-positive at the National Eye Centre, Kaduna, Nigeria.

\section{PATIENTS AND METHODS}

Patients selected for eye surgery during a surgical camp at the National Eye Centre, Kaduna were advised for Voluntary Counseling and Testing (VCT) for HIV and HBsAg to determine their viral status. The Chembio HIV $1 / 2$ STAT-PAK assay was used in venous whole blood. It is a single-use immuno-chromatographic, rapid screening test for the detection of antibodies to Human Immunodeficiency

*Address correspondence to this author at the National Eye Centre, PMB 2267, Kaduna, 8000001, Nigeria; Tel: 234 8035899559;

E-mail:mabalhassan@gmail.com
Virus Types 1 and 2 (HIV 1/2). The result is interpreted as non-reactive or reactive.

Wondo one step HBSAg serum/plasma test strip was used in determining the hepatitis B surface antigen in the serum. It is a rapid immuno-chromatographic assay. It is a qualitative test. A positive result indicates that the presence of $\mathrm{HBsAg}$ is equal to or greater than $1 \mathrm{ng} / \mathrm{ml}$, while a negative test indicates that the level of HB surface antigen is zero of below the detection level of the test.

Patients found to be HBsAg and/or HIV positive were not operated on during the camp.

\section{RESULTS}

A total number of 650 patients including $65.1 \%$ males were screened. The age range was 4 to 96 years with a mean age of 54.4 (SD 12.0). The distributions of the indications for selection were as follows: cataract 483 (74.3\%); glaucoma $44(6.8 \%)$ and pterygium 123 (18.9\%). Two patients $(0.3 \%)$ were found to be HIV seropositive while 11 (1.7\%) were HBsAg positive.

\section{DISCUSSION}

There is a real risk for transmission and spread of HIV and hepatitis B during ophthalmic surgical procedures. The transmission can take place from patient to patient, patient to health care worker or health care worker to patient. This can be through improperly sterilized surgical equipments, contaminated sharps or blood transfusion. Large numbers of ophthalmic surgeries are carried out annually across the world; especially for cataract. In the average cataract, 
surgical rate is around 300 per million population per annum [5].

The traditional medical tests carried before ophthalmic surgeries include fasting blood sugar, complete blood count, bleeding disorders, chest $\mathrm{x}$-ray and electrocardiogram. The aim was to detect systemic conditions that could affect the success of our surgeries and prevent spread of diseases. The benefit or otherwise has been challenged by some ophthalmic Surgeons [6]. Many studies have reported the usefulness or otherwise of pre-operative medical testing before ocular surgery (especially cataract surgery). Schein et al. did not find it useful for cataract surgery in a large study involving 19,150 patients in the USA [6].

In a systematic review, the incidence of adverse events was same in both preoperative testing and no preoperative or selective testing groups. The main adverse events were cardiovascular. The preoperative tests performed were: ECG, complete blood count, and measurement of serum levels of electrolytes, urea nitrogen, creatinine, and glucose [6].

Instead, individualized risk analysis for intra-operative cardiovascular accident should guide the choice for preoperative laboratory test.

It has been suggested that preoperative testing for infectious disease with potential for spread is more useful especially in developing countries where the burdens of these diseases are very high. In this study, we found that $0.3 \%$ of the screened patients were HIV positive while $1.7 \%$ were positive for HBsAg. In a report from Eastern Nigeria, $3.7 \%$ of eye surgical patients were found to be HIV positive at a rural hospital [7].

Authors are not aware of reports of transmission of HIV or hepatitis B during ophthalmic surgery. But viral particle has been reported in donor cornea tissue for transplant [8].

The benefit of determining the status of our patients will include early detection of infected individual for early commencement of treatment and contribute to the total efforts at the surveillance of these diseases. The surgical team will take extra care in preventing from being infected while treating these patients. The standard preoperative and intra-operative techniques for asepsis should however not be compromised whether the patient is sero-positive or seronegative.

Preoperative testing for these two viruses may be more desirable as routine test before intraocular surgery in areas with high prevalence like our environment. This can help in limiting the spread of these two viruses amongst our patients and eye care providers.

There is a need for studies to determine the actual incidence of transmission of these viruses in ocular surgery.

\section{CONCLUSION}

There is a negligible but real risk of transmission of HIV and hepatitis B virus during cataract surgery. Pre-operative screening of all patients going for ophthalmic surgery for $\mathrm{HIV}$ and HbsAg may be desirable in our environment.

\section{CONFLICT OF INTEREST}

The authors confirm that this article content has no conflict of interest.

\section{ACKNOWLEDGEMENTS}

Declared none.

\section{DECLARATIONS}

None of the authors have any relationship with any of the products mentioned in this article.

\section{REFERENCES}

[1] Epidemiological fact sheet on HIV and AIDS; Core data on epidemilogy and response. Available from: www.unaids.org and www.who.int/hiv [Accessed on 29/10/2012].

[2] Egah DZ, Banwat EB, Audu ES, et al. Heptitis B surface antigen, hepatitis C and HIV antibodies in a low risk blood donor group, Nigeria. East Mediterr Health J 2007; 13: 961-6.

[3] Jobarteh M, Malfroy M, Peterson I, et al. Seroprevalence of hepatitis B and C virus in HIV-1 and HIV-2 infected Gambians. Virol J 2010; 7: 230 .

[4] Mabayoje VO, Akinwusi PO, Opaleye OO, Aboderin OA, Egbewale BE, Fagbami AH. Prevalence of hepatitis B surface antigen, hepatitis $\mathrm{C}$ and huma immunodeficiency virus antiboides in a population of students of tertiary institution in Nigeria. Afr $\mathrm{J}$ Clin Exp Microbiol 2010; 11: 68-74.

[5] Foster A. Vision 2020 - The cataract surgery challenge. J Commun Eye Health 2000; 13: 17-19

[6] Keat L, Lindsley K, Tielsch J, Katz J, Schein O. Rountine preoperative medical testing for cataract surgery. Cochrane Database Syst Rev 2009; 2.

[7] Okoye O, MagulikeN, Chuka-Okosa C. Prevalanece of human immunodeficiency virus seropositivity among eye surgical patients at a rural eye care facility in South-Eastern Nigeria. Middle East Afr J Ophthalmol 2012; 19: 93-6

[8] Geier SA, Klauss V, Gurtler L. Human immunodeficiency virus type 1 and type 2 seroprevalence in cornea donors. Ger J Ophthalmol 1994; 3: 182-5. 